\title{
Pelatihan Komunikasi Efektif dalam meningkatkan Pelayanan Prima di Instansi Pemerintahan Provinsi Jawa Barat
}

\author{
Maulana Rezi Ramadhana*1, Ratih Hasanah Sudrajat ${ }^{2}$ \\ 1,2Program Studi Ilmu Komunikasi, Fakultas Komunikasi dan Bisnis, Universitas Telkom \\ *e-mail: rezimaulana@telkomuniversity.ac.id
}

\begin{abstract}
Ineffective communication will affect the quality of a service, because it is related to the speed and accuracy of information that affects public trust. This issue is a focus on the customer service units of service agencies in the West Java provincial government, so it is necessary to increase the capacity of communication directed at excellent service. Community service activities through this form of effective communication training involve twenty-one employees of the customer service unit. Analyze training effectiveness by using score measurements before and after treatment, and needs response surveys are used to assess the usefulness of the training. The results of the training carried out showed a significant increase in scores between before and after the effective communication training, and the training received a positive response. Associated with the results of the training achieved is expected to have an impact on improving the quality of excellent service.
\end{abstract}

Keywords: Training, Effective communication, Excellent Service, Service Unit

\begin{abstract}
Abstrak
Koordinasi kerja yang tidak efektif akan mempengaruhi kualitas suatu layanan, karena terkait dengan kecepatan dan ketepatan informasi yang berdampak pada kepercayaan publik. Persoalan ini menjadi fokus pada unit pelayanan pelanggan di instansi pelayanan terpadu pemerintahan provinsi Jawa Barat, sehingga perlu upaya peningkatan kapasitas komunikasi yang terarah pada kualitas layanan. Kegiatan pengabdian melalui bentuk pelatihan ini melibatkan dua puluh satu pegawai unit pelayanan pelanggan. Efektivitas pelatihan menggunakan pengukuran quasi eksperimental sederhana, dan survei respon kebutuhan digunakan untuk menilai kebermanfaatan pelatihan. Hasil pelatihan yang dilaksanakan menunjukkan adanya peningkatan skor yang cukup signifikan antara sebelum dan sesudah pelatihan, dan pelatihan mendapatkan respon yang positif. Terkait dengan hasil pelatihan yang dicapai tersebut diharapkan berdampak pada peningkatan kualitas pelayanan prima.
\end{abstract}

Kata kunci: Pelatihan, Komunikasi efektif, Pelayanan Prima, Unit Pelayanan

\section{PENDAHULUAN}

Dalam tolak ukur pelaksanaan tugas dan kinerja pemerintah (Maryam, 2016), sektor pelayanan publik diharapkan dapat memberikan layanan yang memenuhi kebutuhan masyarakat (Ratminto, 2006), khususnya kegiatan pelayanan administratif. Oleh karena itu para pekerja pada sektor ini perlu dibekali dengan kemampuan kerja untuk dapat memberikan layanan dengan optimal kepada pelanggan/masyarakat (Mulyawan, 2016), terutama di provinsi Jawa Barat sebagai provinsi zona hijau pelayanan, dan peraih peringkat kedua pelayanan administrasi publik terbaik di tahun 2019 (Solehudin, 2019).

Pelayanan kepada pelanggan adalah salah satu strategi dalam peningkatan pelayanan publik di instansi pemerintah provinsi Jawa Barat, yang dapat memberikan pengaruh terhadap loyalitas dan tingkat kepercayaan masyarakat. Pelayanan kepada pelanggan bukan hanya memberikan yang terbaik, namun turut membina dan mempertahankan pelanggan (baik internal maupun eksternal), adaptif dan dapat meningkatkan kapasitas pribadi dan masyarakat untuk aktif (Ardiansah \& Andrizal, 2019)

Layanan prima di era digital saat ini memang seringkali dihubungkan dengan pemanfaatan digitalisasi sebagai transmisi informasi kepada dan oleh orang lain (Sanchez \& Guo, 2005), selain proses kerja lebih lincah (agile) dan realtime, melalui sistem digital juga dinilai lebih 
konsisten dalam menunjukkan kualitas layanan dibandingkan layanan tradisional biasanya. Sebagai inti dari setiap tujuan pelayanan di instansi, tolak ukur pencapaiannya pelayanan adalah proses yang ditentukan dari kualitas sumber daya manusia sebagai faktor pengelola dan penentunya, sementara kualitas sumber daya manusia dapat dinilai dari beberapa parameter, salah satunya adalah komunikasi. Peran komunikasi pada setiap bagian penugasan harus memiliki pola interaksi yang selaras dalam sebuah layanan, karena komunikasi efektif berpengaruh signifikan terhadap motivasi dan kinerja pegawai (Sarianti, Rasak, \& Anaam, 2018),

Elemen dalam komunikasi seperti komunikator, pesan, media, komunikan, dan efek yang tetap menjadi unsur yang tidak terpisahkan dalam mengkaji masalah komunikasi efektif. Proses komunikasi menentukan kualitas komunikasi, dan masalah di salah satu elemen dapat mengurangi efektivitas komunikasi (Keyton, 2011).

Penelitian sebelumnya telah menjelaskan bahwa keterampilan komunikasi dapat mempengaruhi keefektifan pribadi dan organisasi (Brun, 2010). Selain itu, keterampilan komunikasi secara efektif juga sangat penting untuk mencapai keberhasilan karir seorang petugas pelayanan (Yate, 2009). Dalam kegiatan pelayanan di pemerintahan provinsi Jawa Barat, kualitas pelayanannya dapat tergantung dari bagaimana kualitas pegawai, kualitas pesan, penggunaan media, respon masyarakat, dan efek dalam mengharmonisasikan pola komunikasi tersebut di unit dan bagiannya tersebut. Dengan demikian, komunikasi efektif tetap menjadi kunci tercapainya sebuah pelayanan prima dalam pelayanan publik karena terkait dengan proses penyelesaian masalah (respon) terkait dengan pengaduan dan perizinan.

Gibson, Ivancevich, Donnelly \& Konopaske (2006) menjelaskan bahwa untuk meningkatkan kemampuan interaksi dan komunikasi efektif di organisasi, maka seorang pekerja harus meningkatkan kapasitas diri untuk menguasai informasi yang akan disampaikan, serta mengembangkan kemampuan memahami informasi dari orang lain, dengan mengunakan media yang relevan dengan budaya organisasi. Kegagalan dalam membangun interaksi dan komunikasi didalam organisasi, tentu akan mempengaruhi pada keselarasan kerja yang turut mempengaruhi kualitas pelayanan prima kepada publik, sehingga dapat menghambat aliran informasi dan berdampak pada tingkat kepercayaan publik. Hal ini yang menjadi perhatian unit pelayanan perizinan di instansi pemerintahan propinsi Jawa Barat, sehingga diperlukan sebuah pelatihan tentang komunikasi efektif dalam rangka meningkatkan pelayanan prima.

Dalam organisasi, komunikasi dapat mengalir secara vertikal maupun horizontal dalam sebuah hierarki (Bartels et al. 2010) atau dapat mengalir bebas, dengan semua anggota organisasi berkomunikasi satu sama lainnya (Miller, 2012). Aliran komunikasi ke atas adalah proses penyampaian informasi dari tingkat bawah ke tingkat atas dalam organisasi. Hal ini memberikan kesempatan bagi bawahan untuk berbicara dan memberikan umpan balik dalam pelayanan dan proses pengambilan keputusan (Tourish \& Robson, 2004). Namun demikian, informasi positif di organisasi lebih cenderung mengalir ke atas, yang dapat mengakibatkan masalah potensial pada tingkat bawahan sehingga berdampak negatif pada proses pelayanan dan pengambilan keputusan (Milliken et al, 2013). Hal ini menjadi penting mengingat dalam suatu organisasi, orang-orang yang berasal dari latar belakang sosial dan profesional yang berbeda akan berkumpul untuk bekerja untuk tujuan yang sama.

Menurut Cultip, Allen \& Brrom (2011), komunikasi dapat berlangsung efektif dengan menerapkan Seven Communication (7C) yang terdiri dari completeness (lengkap/komplit), concreteness (konkret), courtesy (sopan), correctness (ketepatan), clarity (jelas), consideration (penuh pertimbangan) dan conciseness (ringkas/padat). Model komunikasi 7C inilah yang menjadi pendekatan dalam pelatihan komunikasi efektif dalam meningkatkan pelayanan di instansi pemerintahan Jawa Barat.

Konsep 7C ini diterjemahkan melalui workshop dan pelatihan, yang diharapkan para pegawai instansi dapat membangun interaksi melalui pola kerja yang dinamis dan selaras pada pencapaian pelayanan prima, tentu hal ini mengarah pada perbaikan dan peningkatan indeks pelayanan di tahun-tahun mendatang. Pengabdian masyarakat ini tidak hanya fokus dalam upaya 
peningkatan kompetensi pada masyarakat sasar, namun juga dalam rangka menggali permasalahan-permasalahan baru dalam sektor komunikasi dan pelayanan publik, yang dapat menjadi topik penelitian dalam lingkup pemerintahan secara nasional, temuan dari hasil solusi (gagasan) penelitian selanjutnya yang dapat dimanfaatkan oleh instansi-instansi di pemerintahan daerah.

\section{METODE}

Pelatihan ini memfokuskan pada sektor penguatan kapasitas sumber daya manusia dalam aspek komunikasi (dan koordinasi) dalam meningkatkan pelayanan prima di instansi pemerintahan provinsi Jawa Barat. Jumlah peserta pelatihan komunikasi efektif ini sebanyak 21 orang dari unit pelayanan pelanggan di instansi pemerintahan provinsi Jawa Barat. Kegiatan pemberdayaan ini menggunakan empat metode, yaitu : (1) Ceramah, sebagai penguatan kemampuan dan penguasaan materi selama 4 jam, (2) Diskusi, merupakan proses penguatan pemahaman dalam bentuk interaksi kelompok selama 4 jam dalam membahas masalah untuk dipetakan bersama hingga merumuskan kesepakatan-kesepakatan tertentu, (3) Latihan, metode pengajaran melalui latihan dan peragaan tentang konsep pemahaman sesuai materi, baik secara individu maupun kelompok. Peserta akan memperagakan cara komunikasi 7C, merasakan dan berlatih untuk menerapkan dalam konteks percakapan komunikasi, (4) Evaluasi, merupakan metode tentang pengukuran penilaian hasil evaluasi diri para peserta, baik dilakukan secara lisan maupun tulisan melalui instrumen evaluasi dalam bentuk kuesioner dan wawancara. Untuk menilai peningkatan perilaku komunikasi, kebermanfaatan dan efektivitas pengabdian masyarakat ini, juga menggunakan umpan balik. Ketercapaian kegiatan ini ditentukan dari parameter pengukuran materi 7C (tabel 1).

Tabel 1. Parameter pengukuran materi 7C

\begin{tabular}{cl}
\hline Aspek 7C & \multicolumn{1}{c}{ Parameter } \\
\hline Correctness & Menggunakan kata-kata yang tepat dan tidak menimbulkan persepsi \\
\hline Conciseness & Menyampaikan inti pesan dgn ringkas \\
\hline Completeness & Menyampaikan informasi dgn lengkap \\
\hline Concreteness & Menyampaikan pesan secara konkrit \\
\hline Clarity & Menyampaikan pesan dengan benar \\
\hline Consideration & Mempertimbangkan pendapat dan pemikiran \\
\hline Courtesy & Menyampaikan pesan dengan tulus dan sopan \\
\hline
\end{tabular}

\section{HASIL DAN PEMBAHASAN}

Pelatihan komunikasi efektif ini dilakukan melalui empat sesi kegiatan, yaitu (1) sesi diskusi (FGD) tentang persoalan yang terkait dengan komunikasi di tempat kerja, (2) pemberian materi 7C bersama dengan latihan praktek komunikasi efektif, dan (3) Evaluasi.

\subsection{Hasil diskusi peserta}

Pada sesi ini dilakukan diskusi kelompok untuk menghasilkan kesepakatan tentang permasalahan komunikasi yang menghambat kinerja pelayanan yang dialami di institusi. Berdasarkan hasil diskusi peserta dirumuskan dua topik, yaitu (1) hambatan komunikasi dalam pelayanan publik, dan (2) pentingnya komunikasi efektif.

\subsubsection{Diskusi 1 : Hambatan komunikasi dalam pelayanan publik}

Shaw (2011) menjelaskan bahwa persoalan terbesar dengan komunikasi adalah persepsi yang dibentuk. Sedangkan Longest, Rakich dan Darr (2000) mengklasifikasikan hambatan ini menjadi dua kategori, yaitu pengaruh lingkungan dan pengaruh personal. Berdasarkan hasil diskusi, hambatan lingkungan dari komunikasi yang umum terjadi antara lain (a) adanya 
kompetisi kerja untuk mendapatkan perhatian atasan, dan (b). Adanya tuntutan kerja untuk cepat sehingga pesan tidak mudah pahami. Sementara hambatan pribadi, antara lain (a) tidak adanya saling perhatian diantara pegawai, sehingga penerima pesan tidak memahami pesan, dan tidak benar-benar mendengarkan, dan (b) adanya persepsi dan orientasi kerja yang berbeda.

\subsubsection{Diskusi 2 : Pentingnya komunikasi efektif dalam pelayanan publik}

Hasil diskusi tentang pentingnya komunikasi efektif mengarah pada empat tema, yaitu (a) Menciptakan kepuasan kerja. Setiap pegawai perlu dimotivasi untuk memberikan ide tentang masalah pelayanan, agar mereka merasa dihargai. (b) Meminimalisir konflik. Konflik di tempat kerja mudah diselesaikan melalui komunikasi yang terbuka dan jelas, komunikasi juga bisa meredam perbedaan. (c) Meningkatkan semangat kerja. Jika seorang petugas perizinan memiliki kejelasan dalam komunikasinya, rekan kerjanya akan paham apa yang diinginkan, dan dapat memberikan tanggapan yang terbaik sesuai kemampuan mereka. Dan (d) Memelihara hubungan kekeluargaan. Komunikasi yang terbuka meningkatkan hubungan pribadi dan profesional.

\subsection{Materi dan praktek}

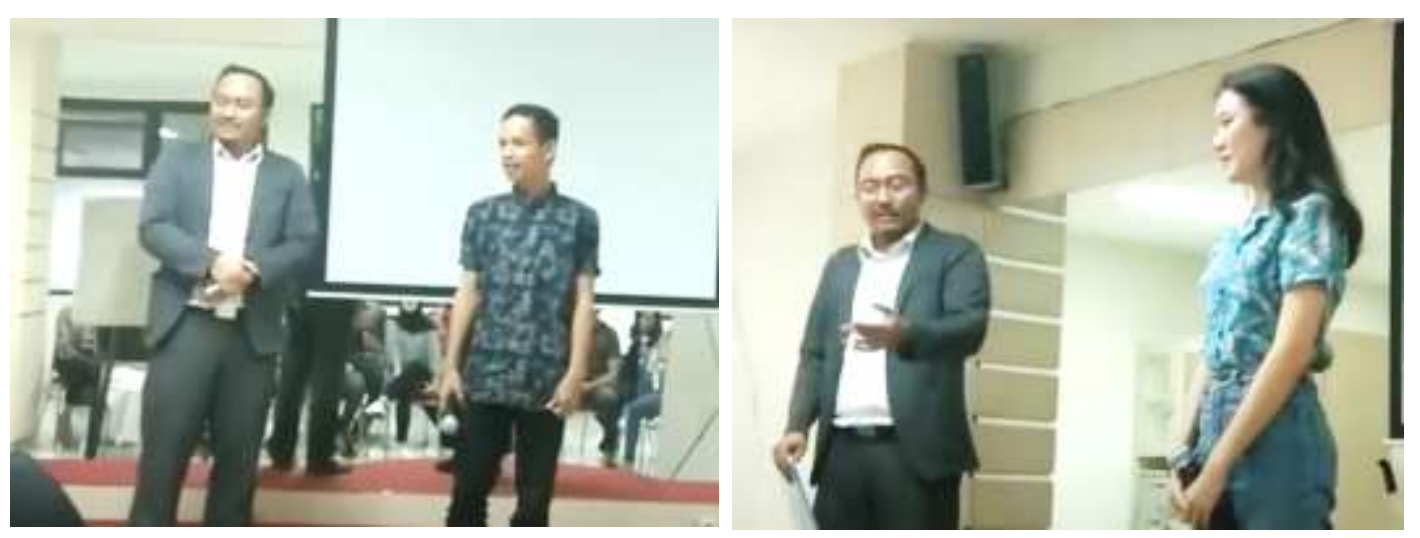

Gambar 1 Penyampaian materi dan latihan

Mengakui tentang hambatan komunikasi dan pentingnya komunikasi efektif berdasarkan pendapat peserta, maka beberapa langkah dalam fungsi komunikasi melalui model 7C digunakan untuk memastikan komunikasi efektif di organisasi. Materi tentang 7C merupakan kompetensi dari komunikasi efektif yang menyediakan daftar parameter yang berguna sebagai komponen bagaimana informasi dihasilkan, baik secara tertulis dan maupun lisan yang disampaikan dengan cara yang jelas, berorientasi pada tujuan, dan terstruktur dengan baik. Materi Seven communication yaitu pemaparan tentang tujuh strategi komunikasi, yaitu :

1. Completeness, inti dari materi ini adalah komunikasi yang lengkap dan menyampaikan semua fakta yang dibutuhkan oleh pelanggan. Pengirim pesan harus mempertimbangkan pandangan pelanggan dan menyampaikan pesan yang sesuai. Hal ini bertujuan untuk mengembangkan dan meningkatkan reputasi organisasi, serta menghemat biaya karena tidak ada informasi penting yang hilang atau tidak ada biaya tambahan yang dikeluarkan untuk menyampaikan pesan tambahan jika komunikasi selesai. Untuk bagian completeness, peserta berlatih untuk menyampaikan informasi kepada rekannya dengan ketentuan : (a) memberikan informasi tambahan, (b). tidak meninggalkan pertanyaan dari penerima, (c). membantu penerima untuk pengambilan keputusan, dan (d). untuk merasakan dalam meyakinkan penerima pesan

2. Concreteness, inti dari komunikasi konkret adalah untuk memperkuat kepercayaan diri dalam membangun relasi dan untuk menghindari agar pesan tidak disalahartikan. Para 
peserta berlatih untuk menyampaikan informasi secara konkret dengan menunjukkan dukungan fakta dan angka tertentu.

3. Courtesy, inti dari komunikasi ini adalah sopan dan santun dalam pesan. Pesan juga harus menunjukkan ekspresi pengirimnnya serta harus menghormati penerimanya. Pengirim pesan harus dengan tulus, bijaksana, reflektif, dan antusias. Peserta berlatih untuk mengirimkan informasi dengan santun yang mempertimbangan pandangan serta perasaan penerima pesan. Melalui pengalaman berlatih ini, pesan yang sopan akan bernilai positif dan fokus pada audiens sebagai upaya untuk menunjukkan rasa hormat kepada penerima pesan.

4. Correctness, inti dari komunikasi ini adalah untuk menegaskan tidak ada kesalahan tata bahasa dalam komunikasi. Peserta berlatih untuk memilah informasi dan menyampaikan informasi dengan pesan yang tepat, benar. Peserta merasakan ketika proses transformasi pesan dilakukan, maka ada kepercayaan diri yang meningkat dan berdampak yang lebih besar pada pelanggan.

5. Clarity, inti dari mater ini adalah kejelasan dalam menyiratkan penekanan pada pesan atau tujuan tertentu pada suatu waktu. Kejelasan dalam komunikasi membuat pemahaman lebih mudah, muncul kejernihan pikiran dan gagasan meningkatkan makna pesan. Pesan yang jelas menggunakan kata-kata yang tepat, tepat dan konkret.

6. Consideration, inti dari materi ini adalah pertimbangan untuk merasakan pandangan orang lain (di posisi orang lain). Materi ini memberikan penegasan tentang komunikasi yang harus mempertimbangkan latar belakang, pola pikir dan tingkat pendidikan, dll. Peserta berlatih untuk menyampaikan informasi dengan memastikan harga diri audiens dipertahankan dan emosi mereka tidak terluka. Peserta juga berlatih untuk mengubah kata-kata dalam pesan agar sesuai dengan kebutuhan audiens sambil melengkapi pesan. Peserta mendapatkan munculnya empati dengan pemberi informasi, dan mereka mempelajari bagaimana membangun optimisme pada penerima, serta belajar untuk lebih sering memberikan kata-kata positif seperti salam, sapa, mengucapkan "terima kasih", menanyakan kabar, dan menawarkan bantuan.

7. Conciseness, inti dari materi ini adalah mengomunikasikan apa yang ingin disampaikan dengan meringkas, tanpa mengubah inti dan pesan informasi. Komunikasi ini bertujuan untuk menghemat waktu sekaligus menghemat biaya, menghindari menggunakan katakata yang berlebihan dan tidak perlu, lebih menarik dan dapat dipahami oleh penerima.

\subsection{Evaluasi}

Pengukuran sebelum dan setelah pelatihan dilakukan untuk melihat nilai evaluasi terhadap pelaksanaan pelatihan. Pengukuran dilakukan kepada 21 peserta dengan merespons item dengan menggunakan skala Likert, mulai dari 1 (sangat tidak setuju) hingga 5 (sangat setuju). Berdasarkan data hasil pengukuran (tabel 2), kemampuan menggunakan kata-kata yang tepat mengalami peningkatan $(+0.66)$ dari sebelum pelatihan, kemampuan menyampaikan inti pesan dengan ringkas mengalami peningkatan $(+0,51)$, kemampuan menyampaikan informasi dengan lengkap mengalami peningkatan $(+0.91)$, kemampuan menyampaikan pesan dengan konkrit mengalami peningkatan (+0.62), kemampuan menyampaikan pesan dengan benar mengalami peningkatan $(+0.91)$, kemampuan mempertimbangkan pendapat dan pemikiran mengalami peningkatan $(+0.85)$ dan kemampuan menyampaikan pesan dengan sopan mengalami peningkatan $(+0.13)$. Dapat disimpulkan bahwa, komunikasi efektif pada petugas pelayanan mengalami peningkatan setelah dilakukan pelatihan komunikasi 7C. 
Tabel 2. Pengukuran skor pemahaman 7C sebelum dan setelah pelatihan

\begin{tabular}{clccc}
\hline & Parameter & $\begin{array}{c}\text { Skor } \\
\text { Sebelum } \\
\text { Kegiatan }\end{array}$ & $\begin{array}{c}\text { Skor Setelah } \\
\text { Kegiatan }\end{array}$ & $\begin{array}{c}\text { Selisih } \\
\text { Skor }\end{array}$ \\
\hline Correctness & $\begin{array}{l}\text { Mampu menggunakan kata-kata } \\
\text { yang tepat dan tidak menimbulkan } \\
\text { persepsi }\end{array}$ & 3,53 & 4,19 & $+0,66$ \\
\hline Conciseness & $\begin{array}{l}\text { Mampu menyampaikan inti pesan } \\
\text { dgn ringkas }\end{array}$ & 3,33 & 3,84 & $+0,51$ \\
\hline Completeness & $\begin{array}{l}\text { Mampu menyampaikan informasi } \\
\text { dgn lengkap }\end{array}$ & 3,23 & 4,14 & $+0,91$ \\
\hline Concreteness & $\begin{array}{l}\text { Mampu menyampaikan pesan secara } \\
\text { konkrit untuk meningkatkan } \\
\text { keyakinan }\end{array}$ & 3,47 & 4,09 & $+0,62$ \\
\hline Clarity & $\begin{array}{l}\text { Mampu menyampaikan pesan } \\
\text { dengan benar }\end{array}$ & 3,42 & 4,33 & +0.91 \\
\hline Consideration & $\begin{array}{l}\text { Mampu mempertimbangkan } \\
\text { pendapat dan pemikiran }\end{array}$ & 3,33 & 4,18 & +0.85 \\
\hline & $\begin{array}{l}\text { Mampu menyampaikan pesan } \\
\text { dengan tulus dan sopan }\end{array}$ & 4,01 & 4,14 & $+0,13$ \\
\hline
\end{tabular}

Tabel 3. Umpan balik kegiatan pelatihan

\begin{tabular}{|c|c|c|c|c|}
\hline \multirow{2}{*}{ Penilaian terhadap Kegiatan } & \multicolumn{4}{|c|}{$\begin{array}{l}\text { Jumlah Masing-masing faktor yang } \\
\text { dipentingkan }\end{array}$} \\
\hline & $\begin{array}{c}\text { Sangat } \\
\text { tidak } \\
\text { setuju }\end{array}$ & $\begin{array}{l}\text { Tidak } \\
\text { Setuju }\end{array}$ & Setuju & $\begin{array}{l}\text { Sangat } \\
\text { Setuju }\end{array}$ \\
\hline $\begin{array}{l}\text { Pelatihan komunikasi efektif ini sesuai dengan } \\
\text { tujuan dari materi komunikasi efektif itu sendiri }\end{array}$ & 0 & 0 & 14 & 7 \\
\hline $\begin{array}{l}\text { Pelatihan ini sudah sesuai dengan kebutuhan } \\
\text { masyarakat sasar dalam pengabdian masyarakat }\end{array}$ & 0 & 0 & 11 & 10 \\
\hline $\begin{array}{l}\text { Waktu pelaksanaan kegiatan ini telah mencukupi } \\
\text { sesuai kebutuhan }\end{array}$ & 0 & 6 & 10 & 5 \\
\hline $\begin{array}{l}\text { Instruktur bersikap ramah, cepat dan tanggap } \\
\text { membantu selama kegiatan }\end{array}$ & 0 & 0 & 9 & 12 \\
\hline \multirow[t]{3}{*}{ Kegiatan ini bermanfaat dalam pelayanan prima } & 0 & 0 & 13 & 8 \\
\hline & 0 & 6 & 57 & 42 \\
\hline & $0 \%$ & $5,7 \%$ & $54,2 \%$ & $40 \%$ \\
\hline Jumlah \% setuju dan sangat & \multicolumn{4}{|c|}{$94,2 \%$} \\
\hline
\end{tabular}


Berdasarkan umpan balik kegiatan pelatihan, sebesar 94,2\% peserta menyatakan bahwa pelatihan komunikasi efektif ini dinilai positif. Hal ini terlihat dari respon positifnya (setuju dan sangat setuju) bahwa pelatihan ini sesuai tujuan materi (100\%), sesuai dengan kebutuhan masyarakat (100\%), kesan instruktur pelatihan $(100 \%)$ dan kebermanfaatan kegiatan dalam meningkatkan kualitas pelayanan (100\%), dan waktu pelaksanaan yang sesuai kebutuhan $(71 \%)$.

Sebagai proses pengiriman informasi dan pemahaman bersama dari satu orang ke orang lain, komunikasi efektif melalui seven communication dinilai penting mengingat setiap fungsi dan kegiatan pelayanan selalu melibatkan beberapa bentuk komunikasi langsung maupun tidak langsung. Dampaknya, untuk meningkatkan efektivitas komunikasi, para pegawai harus mengembangkan kesadaran akan pentingnya tanggung jawab pengirim dan penerima dan mematuhi keterampilan mendengarkan aktif. Keahlian komunikasi yang efektif akan turut meningkatkan pelayanan prima, dengan demikian pegawai unit kerja pelayanan pelanggan harus menciptakan lingkungan yang terencana, berpikir solusi terhadap masalah, pendapat, pemikiran, dan gagasan yang berkaitan dengan pelayanan prima di instansi pemerintahan Provinsi Jawa Barat.

\section{KESIMPULAN}

Berdasarkan hasil pelatihan komunikasi efektif yang telah dilakukan, dapat disimpulkan sebagai berikut :

- Rumusan hasil diskusi tentang hambatan komunikasi dan pentingnya komunikasi efektif telah menggambarkan adanya respon positif dari peserta terkait dengan permasalahan komunikasi yang dialami di instansi.

- Peningkatan skor komunikasi 7C antara sebelum dan setelah pelatihan telah menggambarkan bahwa pelatihan komunikasi efektif ini mampu meningkatkan kemampuan dalam komunikasi efektif.

- Berdasarkan hasil umpan balik peserta dengan tingkat kepuasan peserta mencapai 94,2\% menandakan bahwa pelatihan ini mendapat apresiasi baik dan dinilai positif.

\section{SARAN}

Pelatihan komunikasi efektif dengan menggunakan modul seven communication dalam meningkatkan pelayanan prima dapat memberikan dasar yang baik untuk mengembangkan dan memelihara keterampilan komunikasi efektif di lingkungan pegawai unit pelayanan pelanggan. Namun demikian, pelatihan ini masih belum optimal dalam pengelolaan waktu dan durasi, sehingga perlu lebih mematangkan kurikulum dengan durasi yang lebih panjang. Sementara penerapan komunikasi efektif dalam pekerjaan rutin tampk harus dievaluasi secara berkala, mengingat keluhan-keluhan pelanggan yang muncul memungkinkan membutuhkan penguasaan dan kemampuan komunikasi yang berbeda. Tindaklanjut kegiatan pelatihan ini dapat dilakukan melalui metode diskusi sebagai kegiatan pendampingan, sehingga peserta dapat lebih terbantu dan saling membantu ketika menghadapi persoalan dalam pelayanannya. Akhirnya model komunikasi efektif ini diharapkan dapat menjadi protokol dalam prosedur pelayanan publik di instansi pemerintahan provinsi Jawa Barat.

\section{DAFTAR PUSTAKA}

Ardiansah, \& Andrizal. (2019). Penyelenggaraan Pelayanan Publik Berdasarkan UndangUndang Tentang Pelayanan Publik di Kecamatan Mempura Kabupaten Siak. Dinamisia: $\begin{array}{llll}\text { Jurnal Pengabdian } \quad \text { Kepada } & \text { Masyarakat, } & \text { 368-377. }\end{array}$ https://doi.org/10.31849/dinamisia.v3i2.3474 
Bartels J, Peters 0, de Jong M, Pruyn A, van der Molen M. (2010). Horizontal and vertical communication as determinants of professional and organizational identification. Personnel Review, 39(2):210-26.

Brun, J. P. (2010). Missing pieces: 7 ways to improve employee well-being and organizational effectiveness. New York, NY: Palgrave Macmillan.

Cutlip, Scoot M., Allen H. Center, dan Glen M. Broom. (2011). Effective Public Relations, Edisi Kesembilan. Jakarta: Kencana

Gibson.J.L, Ivancevich. M.J, Donnelly. J.H \& Konopaske. R (2006): Organizations Behavior, Structure, Process International Edition. Asia: McGraw Hill Education

Keyton, J. (2011). Communication and organizational culture: A key to understanding work experience. Thousand Oaks, CA: Sage.

Longest, B. B., Rakich, J. S., \& Darr, K. (2000). Managing health services organizations (4th ed.). Baltimore: Health Professions Press, Inc.

Maryam, N. S. (2016). Mewujudkan good governance melalui pelayanan publik. Jurnal Ilmu Politik dan Komunikasi: Politeknik Kridatama Bandung

Miller K. (2012) Organizational communication: Approaches and processes. Boston, MA: Wadsworth Cengage Learning

Milliken FJ, Morrison EW, Hewlin PF. (2003). An Exploratory Study of Employee Silence: Issues that Employees Don't Communicate Upward and Why. Journal of Management Studies, 40(6):1453-76.

Mulyawan, R. (2016). Profesionalisme Aparat Dan Kapasitas Kelembagaan Dalam Pelayanan Publik Di Provinsi Jawa Barat. CosmoGov: Jurnal Ilmu Pemerintahan, 2(2), 201-219.

Ratminto, (2006) Manajemen Pelayanan. Yogyakarta: Pustaka Pelajar, 2006

Sanchez, Y. \& Guo, K.L. (2005). Workplace Communication. Boston, MA: Pearson

Sarianti, W., Rasak, A., \& Anaam, N. (2018). Pengaruh Budaya Organisasi dan Komunikasi Efektif terhadap Motivasi dan Kinerja Pegawai pada Sekretariat DPRD Provinsi Sulawesi Tenggara. Sigma: Journal of Economic and Business, 1(1), 24-45.

Solehudin, M. (2019, March 21). Pelayanan Administrasi Publik, Ridwan Kamil: Jabar Terbaik Kedua. Retrieved from https://news.detik.com/berita-jawa-barat/d-4477609/pelayananadministrasi-publik-ridwan-kamil-jabar-terbaik-kedua

Tourish D, Robson P. (2004). Critical upward feedback in organisations: Processes, problems and implications for communication management. Journal of Communication Management, $8(2): 150-67$

Yate, M. (2009). Hiring the best: A manager's guide to effective interviewing and recruiting. Cincinnati, OH: F \& W Media 